\title{
On Fositive-Definiteness of Inertial Mass, Nonpositive-Definiteness of Electromagnetic Coupling and the Mach Principle from General Relativity.
}

\author{
M. SACHS \\ Department of Physics, State University of New York - Buffalo, N.Y. \\ (Nuovo Cimento, $53 \mathrm{~B}, 398(1968)$ )
}

Please replace the equation on p. 411 which reads $\operatorname{det} A_{+}= \pm \operatorname{det} A_{-}+K$ with the equation

$$
\ln \left|\operatorname{det} \Lambda_{+}\right|=\ln \left|\operatorname{det} \Lambda_{-}\right|+K \text {. }
$$

\author{
$\left.{ }^{6} \mathrm{Li}, \gamma, \mathrm{t}\right)^{3} \mathrm{He}$ and ${ }^{6} \mathrm{Li}(\gamma, \mathrm{pd})^{3} \mathrm{H}$ Reactions. \\ A. Murakami \\ Department of Physies, Saga University - Saga \\ (Nuovo Cimento, $55 \mathrm{~B}, 604(1968)$ )
}

A critical misprint appears in the caption of Fig. 2. The solid line should stand for the ${ }^{6} \mathrm{Li}(\gamma, \mathrm{t})^{3} \mathrm{He}$ cross-section, not the ${ }^{6} \mathrm{Li}(\gamma, \mathrm{pd})^{3} \mathrm{H}$ eross-section, and the dotted line, vice versa. On page 606 , line $7, b$ ) should read $a$ ). On page 607,6 th and 10 th lines from the bottom, "amounts to $128 \mathrm{mb} \cdot \mathrm{MeV}$ * and " $128 \mathrm{mb} \cdot \mathrm{MeV}$ can be ..." should read "amounts to $126 \mathrm{mb} \cdot \mathrm{MeV}$ " and " $126 \mathrm{mb} \cdot \mathrm{MeV}$ can be ...", respectively. 